NJE Vol. 36: 64-70, 2020

Nigerian Journal of Entomology

Published by the Entomological Soc. of Nig.

www.esnjournal.com.ng

DOI.10.36108/NJE/0202/63.01.70

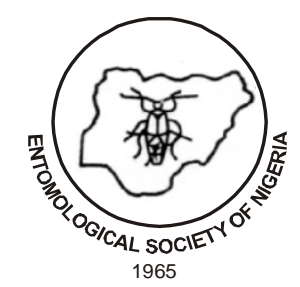

\title{
Residual Content of Persistent Insecticides in the Fresh Nuts of Cola Acuminata Cohac from Kumbotso Local Government Area of Kano State and Implication for Public Health
}

\author{
${ }^{1}$ Alkali, Z.D. and ${ }^{2}$ Abdullahi, N. U. Malik ${ }^{1}$, L.J. Bamaiyi ${ }^{2}$, A.Y. Mahmoud ${ }^{3}$ \\ and A.I. Ahmed ${ }^{1}$ \\ ${ }^{1}$ Pest Management Technology (DAC), Ahmadu Bello University, Zaria \\ ${ }^{2}$ Crop Protection, Faculty of Agriculture, Ahmadu Bello University, Zaria \\ ${ }^{3}$ Chemistry Department, Ahmadu Bello University, Zaria
}

\begin{abstract}
The pesticide residues in kola nut, Cola acuminata obtained from Mariri Market, Kumbotso Local Government Area, Kano state of Nigeria was investigated. The study consisted of a survey and laboratory analysis of kola nut samples. One hundred structured questionnaires were administered through an open market format in the major kola nut market in the state. In addition, $1 \mathrm{~kg}$ sample of kola nut was collected randomly from ten major kola nut sellers in the market for analysis. A $100 \mathrm{~g}$ sample of the kola nut was pounded into paste in a blender of which $50 \mathrm{~g}$ was soaked in $150 \mathrm{~mL}$ acetone for $24 \mathrm{~h}$. The extracted sample was filtered through anhydrous sodium sulfate while the extract was evaporated to near dryness using a rotary evaporator at $28^{\circ} \mathrm{C}$ in the Laboratory. Residue was redissolved in $2 \mathrm{~mL}$ acetone and kept in the refrigerator for GCMS Analysis. Ten pesticidal compounds were detected from a comparison of data with reference to mass spectrometry data (NIST05.LIB) and significant occurrence in kola nut sample which had a corresponding molecules affiliated to some pesticides standards were detected in the sample
\end{abstract}

Keywords: Cola acuminata, Pesticide residue, Persistent insecticide.

\section{INTRODUCTION}

Fresh Kola nut is mainly chewed because of its stimulant characteristics. The proximate content of Kola nut includes about $1 \%$ protein, $1.35 \%$ fats and $45 \%$ starch. While its secondary metabolite constituents include caffein, theobromine, tannins, phenolics,

*Correspondence email:

Usmanmalik2016@gmail.com kolatin and kolanin (Quarco, 1973). The presence of alkaloids and other phytochemicals makes kola nut suitable as raw materials for the manufacture of pharmaceutical products and beverages while the tannin content is a good source of dyes in textiles and thread (Petu-Ibikunle et al., 2010).

Nigeria produces about $70 \%$ of world's kola nut with an annual estimated production 
of 200,000 metric tonnes of fresh nuts, mostly from South west, Nigeria $(\mathrm{CBN}$, 2002). The South west accounts for about $88 \%$ of the total production; while only about $10 \%$ of the produce is exported, and the rest are consumed locally (Oluokun and Oladokun, 1999. Kola nut also has industrial usage for the production of wines, candles, beverages, drugs, soft drinks, animal feed formulation, liquid soap and dyes (Daramola, 1973). It is believed to dispel sleep, hunger and thirst and act as an anti-depressant. Tachie-Obeng and Browns (2006) observed that beverage could be made by boiling the powdered seed in water.

In Nigeria, kola nut is regarded in high esteem and as such often offered as a gift to traditional leaders and visitors. In northern Nigeria, where the bulk of kola nut is chewed, it is greatly relished as a stimulant in substitute for alcoholic drinks. As a result, there is a heavy trade of kola from the humid southern regions to the northern arid parts of West Africa. However, the insect pests of kola nut are the weevils, Balanogastris kolae and Sophrorhinus spp. They are field-tostore pests which can cause up to $100 \%$ loss if left uncontrolled in storage (Asogwa et al., 2008).

Consequently, kola nuts storage is usually laborious because the freshness of the nuts needs to be maintained for several months. Petu-Ibikunle et al. (2010) observed that the major obstacle encountered in kola nut business is basically storage facilities with insect pest causing $53.33 \%$ loss which causes reduction in the value and invariably the price of stored kola nuts.

Chlorpyrifos and diclorvos are directly applied to the kola nut for purpose of storage. However, this leaves Pesticides such as Lambdacylohathrin, Cypermethrin, Dimethoate and Chlorpyrifos are often recommended against insect pests of food crops because, they displayed a broad spectrum of insecticidal activity coupled with low mammalian toxicity and low application rates for insect. This attribute makes them environmentally more acceptable than the older, more persistent and toxic organochlorine and organophosphorus insecticides. However they leave residues on food product (Cameron and Walter, 2000). Evaluation of pesticide residues in food is of public health importance and would help to ensure that residues are kept within safe limits (Ogah et al., 2011).

Dietary intake constitutes the most common and principal pathway of exposure to pesticides and human exposure to pesticides through contaminated food intake can cause chronic and acute toxicities (Liu et al., 2016). Thus, regular surveys and monitoring programmes of pesticide residues coupled with risk assessments have been carried out and reported in many developed countries worldwide, and this is done in order to protect consumer health, improve the management of agricultural resources and prevent economic losses in West Africa, many studies have reported contamination levels of pesticide residues in fruits and vegetables and in maize and cowpea (Akoto et al, 2013).

In Nigeria, several studies have also reported high levels of pesticide residues in fruits, vegetables and other food produce, on cocoa and on kola nut as well as seafood products (Aikpokpodion et al., 2013). The present study was conducted to determine the pesticide residues content in kola nut, Cola acuminata from Mariri Market, Kumbotso Local Government Area of Kano State, Nigeria.

\section{MATERIAL AND METHODS}

\section{Experimental Site}

The behavioural survey was conducted at Mariri market $\left(11^{\circ} 54^{\prime} 2.27^{\prime \prime} \mathrm{N}\right.$ and $8^{\circ} 30^{\prime}$ 
58.79”E), Kumbotso Local Government Area of Kano State while laboratory analysis was conducted at the Multi-user Laboratory, Chemistry Department, Ahmadu Bello University, Zaria, Kaduna State and National Research Institute for Chemical Technology (NARICT), in Zaria, Kaduna State, Nigeria.

\section{Collection of Primary Data}

A total of 100 structured questionnaires was administered in the market to conduct oral interviews to kola nut sellers on the types of pesticide used for preservation, method of application, reasons for choosing the pesticide and length of storage of the kola nut after pesticide application.

\section{Collection of Kola nut samples and Laboratory Analysis}

Kola nut samples (1g) were s collected randomly from ten (10) different sellers within the market. The collected sample was the representative of the entire kola nut present in the market. The sample collected $(1 \mathrm{~kg})$ was put in a polythene bag, labeled and transferred to the laboratory for further analysis following the method of Islam et al. (2009).

\section{Sample Extraction and Gas Chromatographic Analysis}

A $100 \mathrm{~g}$ sample of the kola nut was ground into paste, out of which $50 \mathrm{~g}$ was chopped and macerated in a blender. The ground paste was dipped in $150 \mathrm{~mL}$ acetone and kept overnight (Singh et al., 2007). The extracted sample was filtered through anhydrous sodium sulfate and the resulting extract was evaporated to near dryness using a rotary evaporator at a temperature ranging between 26 to $28^{\circ} \mathrm{C}$ at the Multi User Laboratory, Ahmadu Bello University, Zaria (Barakat et al., 1994). A $50 \mathrm{ml}$ sample of the $0.2 \mathrm{mg} / \mathrm{ml}$ of the pesticides stock solution was added to
$150 \mathrm{ml}$ of the extracted kola nut sample. A stock solution of triphenylmethane (TPM) in acetonitrile at concentration of $1 \mathrm{mg} / \mathrm{mL}$ was used as internal standard. An aliquot of 20 $\mu \mathrm{L}$ of TPM solution in acetonitrile (1000 $\mathrm{mg} / \mathrm{L}$ ) was added to the spiked sample as internal standard.

Furthermore, 1 ul of the kola nut sample was injected into the GC (Shimadzu GCMS (QP 2010 plus with universal detector)) column RTX, $30 \mathrm{~m} \times 0.25 \mathrm{~mm} / \mathrm{d}$, with 0.25 $\mu \mathrm{m}$ film thickness (5\% diphenyl, 95\% dimethyl polysitoxane), and observed for 5 minutes, within which the peaks and the areas under them were recorded per retention time

\section{RESULTS}

Table 1 showed the level of knowledge and usage of pesticides for post harvest operations. A total of $94 \%$ of the respondents confirmed knowledge and usage of pesticides for storing kola nut produce. while 6\% indicated that they do not use pesticide for storing kola nut. In all, a total of five synthetic insecticides namely: chlorpyrifos, cypemetrin, dichlorvos, dimethoate, profenofos, and dieldrin, were encountered in the study as major residues of kola nut in Kumbotso Local Government of Kano state. Dimethoate was not detected in the samples studied. The result revealed that Chlorpyrifos $26.82 \%$ and Dichlorvos $25.12 \%$ were the main pesticides used in storing kola nut in the study area followed by Dieldrin with $16.81 \%$. The choice of the various pesticides was largely based on availability according to $58 \%$ of the respondents. Respondent's choice of pesticides based on custom was $22 \%$, while those choosing on the basis of ease of application were $17 \%$.

Five major insecticides listed in Table 2 from three groups: organochlorines, organophosphate and pyrethroids were found while 
dimethoate was not detected. Of these, chlorpyrifos was the most abundant accounting for $40 \%$ of total residues detected.

\section{Pesticide residues in the Kola nut, Cola acuminata}

Ten pesticidal compounds were detected from a comparison of data with reference to mass spectrometry data (NIST05.LIB) and significant occurrence in kola nut sample which had a corresponding molecules affiliated to some pesticides standards were detected in the sample as shown in Table 3.

Table 1: Knowledge of Pesticide and usage in Mariri Market

\begin{tabular}{lll}
\hline Variables & Frequency & Percentage \\
\hline Heard of Pesticides & 269 & 93.73 \\
Not heard of Pesticides & 18 & 6.27 \\
Total & $\mathbf{2 8 7}$ & $\mathbf{1 0 0 . 0 0}$ \\
Types of Pesticides Used & & \\
Dichlorvos (DD Force). & 98 & 25.82 \\
Phostoxin & 59 & 14.11 \\
Lambdacyhalothrin & 27 & 6.44 \\
Cypermethrin & 16 & 3.29 \\
Dimethoate & 23 & 4.72 \\
Chlorpyrifos & 116 & 26.12 \\
Dieldrin & 77 & 16.81 \\
Cold storage/packaging materials & 3 & 0.62 \\
Reasons for Selecting the Pesticides & & \\
Custom & 62 & 21.60 \\
Availability & 168 & 58.53 \\
Ease of usage/use & 48 & 16.72 \\
Others & 6 & 2.62 \\
\hline
\end{tabular}

Table 2: Shows the summary of significant occurrence of pesticide in the kola nut sample in comparison with reference to mass spectrometry data

\begin{tabular}{lll}
\hline S/No & Pesticides & Kola nut \\
\hline $\mathbf{1}$ & Dieldrin & $\sqrt{ }$ \\
$\mathbf{2}$ & Chlorpyrifos & $\sqrt{ } \sqrt{ } \sqrt{ }$ \\
$\mathbf{3}$ & Cypermethrin & $\sqrt{ }$ \\
$\mathbf{4}$ & Dichlorvos & $\sqrt{ } \sqrt{ }$ \\
$\mathbf{5}$ & Profenofos & $\sqrt{ }$ \\
$\mathbf{6}$ & Dimethoate & ND \\
\hline
\end{tabular}

$\mathrm{ND}=$ Not Detected 
Table 3: Corresponding molecule of kola nut sample with reference to mass spectroscopy data

\begin{tabular}{|c|c|c|c|c|}
\hline Line & $\begin{array}{l}\text { Retention } \\
\text { Time } \\
\text { (min.) }\end{array}$ & $\begin{array}{l}\text { Base peak } \\
\text { fragment } \\
\mathrm{m} / \mathrm{z}+\end{array}$ & Corresponding molecule & $\begin{array}{l}\text { Corresponding } \\
\text { pesticides } \\
\text { standard } \\
\end{array}$ \\
\hline 1 & 31.275 & 161.15 & 1-(4-methoxyphenyl)-4-methyl-1-penten-3-one & Cypermethrin \\
\hline 2 & 32.225 & 194.15 & Tetrahydrocytisine & Chlorpyrifos \\
\hline 3 & 33.812 & 194.20 & 2-bromo-1,3-difluorobenzene & Profenofos \\
\hline 4 & 54.228 & 207.15 & $\mathrm{~N}$-methyl-4-chlorobenzenesulfonamide & Dieldrin \\
\hline 5 & 55.278 & 207.15 & 2-benzyloxy-beta-dimethylalmino-6-nitrostyrene & Chlorpyrifos \\
\hline 6 & 57.635 & 208.15 & Ethyl- $\alpha$-fluoro-4-methylcinnamate & Dichlorvos \\
\hline 7 & 57.725 & 208.15 & Ethyl- $\alpha$-fluoro-4-methylcinnamate & Chlorpyrifos \\
\hline 8 & 58.550 & 227.25 & Methylesterpalmitic acids & Diclorvos \\
\hline 9 & 67.693 & 253.15 & $\begin{array}{l}\text { 12,13-epoxy-3,4,7,15-tetrahydroxy-( } 3 \text {,alpha,4- } \\
\text { beta,7-alpha)trichothec-9-en-8-one }\end{array}$ & Dieldrin \\
\hline 10 & 57.577 & 253.10 & $\begin{array}{l}\text { 1,3,5-trimethoxy-2-(1Z)-2-nitro-1- } \\
\text { propenylbenzene }\end{array}$ & Chlorpyrifos \\
\hline
\end{tabular}

The most highly concentrated pesticide in the fresh kola nut was Chlorpyrifos $(0.076+0.011 \mathrm{mg} / \mathrm{kg})$ and this concentration was higher than the European maximum tolerable residue limit of $0.0001 \mathrm{mg} / \mathrm{kg}$. Also the concentration of the pesticide residue detected in the sample include cypermethrin $0.001143 \pm 0.000484 \mathrm{mg} / \mathrm{kg}$ profenofos
$0.003166667 \pm 0.001814754 \mathrm{mg} / \mathrm{kg}$, dichlorvos $0.025 \pm 0.0043589 \mathrm{mg} / \mathrm{kg}$ and dieldrin, $0.003 \pm 0.00349476 \mathrm{mg} / \mathrm{kg}$. Amongst the entire pesticides residue, only dieldrin, cypermethrin and profenofos were much lower compared than the European maximum residue limit for each of the residue.

Table 4: Pesticides residue in Kola nut sample

\begin{tabular}{lllllll}
\hline & \multicolumn{3}{c}{ Organophosphorus pesticides } & \multicolumn{2}{c}{$\begin{array}{c}\text { Organochlorine } \\
\text { pesticides }\end{array}$} & $\begin{array}{l}\text { Pyretheroids } \\
\text { pesticides }\end{array}$ \\
\hline Mean value & Chlorpyrifos & Dimethoate & Profenofos & Dieldrin & Dichlorvos & Cypermethrinn \\
Mariri $(\mathrm{mg} / \mathrm{kg})$ & 0.0786 & ND & 0.0029 & 0.0043 & 0.02 & 0.001 \\
EUMRL $(\mathrm{mg} / \mathrm{kg})$ & 0.05 & 0.01 & 0.05 & 0.01 & 0.01 & 0.07 \\
\hline
\end{tabular}

EU MRL= European Union Maximum Residue Limit

\section{DISCUSSIONS}

In the first phase of the study, the survey revealed the level of knowledge and pesticide usage in the study area, types of pesticides used and reasons for selecting pesticides. The result shows that $93.7 \%$ have heard of pesticide while only $6 \%$ never heard of it at all. This shows that majority of the traders in the study area use pesticide for kola nut preservation to enhance its shelve life. This is in agreement with the findings of Olabode et al 2011 which says pesticide have served as a tools to enhance the shelve life of agricultural produce. The predominance of chlorpyrifos (26\%) and dichlorvos (25\%) in an open market indicated that they are widely used in protection of fresh Kola nut against insect pests. The frequency of these pesticides indicated that they are still available in Mariri market. 
Most of the detected compounds in the fresh kola nut sample were organophosphorus pesticide (chlorpyrivos) and Organochlorine pesticide (dichlorvos). Ten compounds were detected from comparism of data with reference to mass spectrometry data. (NIST. Lib) and significant occurrence in the sample which had a corresponding molecules affiliated to some pesticide standard detected in fresh kola nut. Chlorpyrifos was the most frequently detected in the sample $(n=4)$, while dichlorvos $(n=2)$. Their detection was not surprising as they are commonly used as post harvest pesticides on kola nut in the study area. The presence of these pesticides residue in kola nut could be attributed to the inappropriate application such as over dosage of the said pesticides and indiscriminate acts to achieve set goals (Chedi et al 2010).

Improper use of pesticide may result in high Pesticide residue above the EUMRLs that will be hazardous to the consumer and lead to the emergence of resistant pest populations which would be insensitive to normal pesticide dosage (Chedi et al., 2010).

Since kola nut are eaten raw in all cultures, and most of the pesticides made to preserve kola nut are been applied directly, this lead to the contamination of the kola nut.

The pesticide residues in the kola nut samples revealed that chlorpyrifos and dichlorvos have the higher mean concentrations above the EUMRLs which might be due to the post-application of this pesticides after harvest in the study area. This also supports Li, (2009) from Zimbabwe who says that illiteracy, poor or bad attitude of farmers on danger of pesticides contributed to higher level of dichlorvos. Hence, this could be a similar trend happening at Mariri market in Kano State. Although, profenofos and dieldrin are below tolerable limit of EUMRLS.
The detection of pesticides in the kola nut samples agrees with the report of Khuhro and Nizamani (2000), which states that the farmers repeatedly spray different pesticides on food crops to protect their crop from various pests without any awareness about their hazardous effect on health. It is also routine practice of farmers to send their produce to market based on the demand which causes contamination of residues beyond EUMRLs.

\section{CONCLUSION}

In conclusion, the result of the study established that $93.73 \%$ of the traders heard of pesticide in Mariri market. However, the survey also revealed that the major pesticide used in preserving their kola nut were chlorpyrifos (26.12\%) and dichlorvos $(25.82 \%)$. while the choice of pesticide usage was based on availability of the pesticide in the study area.

It also showed that ten different compounds were detected in kola nut in the market. The observed pesticide residues for chlorpyrifos and dichlorvos in kola nut in the study area were above the EU MRLs. Hence, there is urgency in need by federal government to train respondents on pesticide storage, the dosage and time of application to minimize the pesticide residues within the EU MRLS, and for consumer safety and to add value to our kola nut in the international market.

\section{REFERENCES}

Akoto, O., Anoloh, H., Danko, Eshura., G. and Osei-Fosu, P. (2013). Heath risk assessment of pesticides residues in maize and cowpea from Ejura, Ghana. Cemosphere, 92: 67-7.

Aikpokodion P.E., Oduwole O.O, and Adebiyi S. (2013). Appraisal of pesticide residues in Kola nut obtained from selected markets in 
south western Nigeria, Journal of Scientific Research and Reports, 2(2): 582-597.

Asogwa, E. U., Ojelade, K. T. M., Anikwe, J. C. and Ndubuaku, T. C. N. (2008). Major kola insect pests. In: Insect pests of cocoa, kola, coffee, cashew, tea and their control. Answers Communication Concepts, Apapa, Lagos, Nigeria. pp. 57-60.

Barakat, A. A., Abdalla, S. A. Badawy, H. M. A. Sammour, E. A. and Soliman, M. M. M. (1994). Persistence of profenofos and pirimiphos methyl in green cowpea pods and on films exposed to Ultra-violet and sun rays. Bulletin of Entomological Society. 21: 103-111.

CBN (2002). Memorandum on Agricultural Financing. Presented at the 32nd regular meeting the National Council on Agricultural and Rural Development held at Yola, Adamawa State. Central Bank of Nigeria, p. 10.

Cameron, P. J. and Walker, G. P. (2002). Tomato fruitworm resistance management strategy. NewZealand Institute for Crop and Food Research Limited, Auckland, New Zealand.

Chedi, B. A. Z. and Aliyu, M. (2010). Effect and Management of acute dichlorvos poisoning in wistar rats. Bayero Journal of Pure and Applied Sciences 3(2): 1-3.

Daramola, A. M. (1973). The bionomics of kola weevils, Sophrorhinus spp. (Coleoptera: Curculionidae) Ph.D. Thesis, University of Ibadan, Nigeria. 325p.

Islam, S., Hossain, M. S., Nahar, N., Mosihuzzaman, M. and Mamun, M. I. R. (2009). Application of high Performance Liquid Chromatography to the analysis of pesticide residues in egg plants. J. Applied Sci., 9(5): 973-977.
Khuhro, R. D. and Nizamani, S. M. (2000). Monitoring pesticide residues in fruits and vegetables. Report submitted to EPA, Karachi. 51p.

Liu, Y., Shen, D., Li, S., NI, Z., Ding, M., YE, C. and Tang, F. (2016). Residues assessment of pesticides in nut of chira. Cemosophere, 144:645-651.

Ogah, C. O., Corker, H. A. and Adepelu-Bello, A. A. (2011). Pesticides residues level in maize sample from markets in Lagos State, Nigeria. Nigerian Q. J. Hosp Med, 21(3): 167-174.

Oluokun, J. A. and Oladokun, M. A. O. (1999). The effects of graded levels of brewers spentgrain and kola nut pod meal in the performance characteristics and carcass quality of rabbits. Niger. J. Anim. Prod., 26: 71- 77.

Petu-Ibikunle, A. M., Esther, W., Audu, A. and Shallagwa, Y. Y. (2010). Assessment of damage and losses to kola nut weevils, Balanogastris kolae (Desbr) Coleoptera: Curculionidae. Afr. J. General Agric., 6(1): $1-5$.

Quarco, T. (1973). A handbook on Kola.CRIN., Ibadan. 90 pp.

Singh, P. B., Singh, V. and Nayak, P. K. (2008). Pesticide residues and reproductive dysfunction in different vertebrates from north India. Food ChemToxicol, 46(7): 2533-2539.

Tachie-Obeng, E. and Brown, N. (2006). Cola nitida and Cola acuminata: A state of knowledge report undertaken for the Central African Regional Program for the Environment. Oxford Forestry Institute, Department of Plant Science, University of Oxford, United Kingdom. 37p.
NJE Vol. 36: 64-70, 2020

Nigerian Journal of Entomology

Published by the Entomological Soc. of Nig.

www.esnjournal.com.ng

DOI.10.36108/NJE/0202/63.01.70

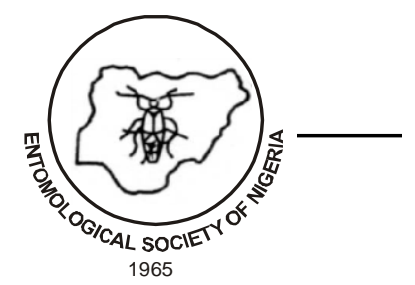

